\title{
Coaching Effectiveness: Coach and Coachee Characteristics that Lead to Success
}

\author{
Sheila M. Boysen \\ Illinois, USA
}

\begin{abstract}
Today, coaching serves as a common and widely employed leadership development and organizational performance enhancement intervention. The literature shows that coaching produces positive outcomes, yet far less is known about how these positive outcomes are produced. This study organizes what is known to date, as represented in the scholarly literature, about the multitude of competencies that have been reported to lead to effective executive coaching experiences. These known competencies were used as the basis of the survey in this study. The results of this quantitative study represent the voices of 157 International Coach Federation certified coaches and 70 of their coachees across sixteen countries and indicate that effectiveness in executive coaching is the shared responsibility of the executive coach and the coachee. This study presents the top seven most commonly cited competencies from the coach's and coachee's perspectives, necessary for the highest level of effectiveness. These top competencies are organized by competency area and are represented visually in a coaching effectiveness model.
\end{abstract}

Keywords: coaching effectiveness, organizational performance, leadership development, coaching outcomes

\section{Introduction}

This paper describes the results of a study to determine the skills and characteristics that lead to effective executive coaching engagements. This study utilized a survey research design to determine the characteristics that most commonly lead to an effective coaching experience, from the coach's as well as the coachee's perspective.

The primary research question that guided this study was, "What specific characteristics in executive coaching lead to the most effective coaching experiences for the coachee and which are the most frequently cited characteristics that contribute to the overall effectiveness of coaching from the perspective of the coach?"

This is an Open Access article distributed under the terms of the Creative Commons Attribution (CC BY) License which permits use, distribution and reproduction in any medium, provided the original work is properly cited. 
Practicing and embodying the ICF Core Competencies is important for any coach. However, additional skills have surfaced that contribute to an effective coaching engagement. There are also characteristics and skills that are important for the coachee to possess. First, the criteria that are used for selecting a professional coach as well as the coaching characteristics that have shown to contribute to effectiveness through the existing body of coaching literature will be discussed. Finally, the results of the study and the Coaching Effectiveness Model will be presented.

\section{Criteria Sought When Selecting a Professional Coach}

The Corporate Leadership Council (CLC) (2017) reports that organizations highly value a coach's prior experience with coaching professionals, along with training in organizational/industrial psychology or a related field. More specifically, the CLC reports that the skills most sought when selecting a professional coach include the following: strong coaching experience ( $90 \%$ of respondents); degree in psychology or related field (55\% of respondents); coaching qualifications or certifications (52\% of respondents); experience working as part of a team (27\% of respondents); experience working in a line-management position (19\% of respondents); experience running a business ( $16 \%$ of respondents); and experience working in the industry similar to the coachee's organization ( $6 \%$ of respondents).

In another report, findings of 87 professionals who have had a coach report the following sought-after credentials and experience criteria when selecting a coach: $82 \%$ reported a preference that their coach had completed graduate studies in psychology or a related field, $78 \%$ reported a preference that their coach had experience in or understanding of business, and 25\% reported a preference that their coach had an established reputation as a coach (Wasylyshyn, 2003).

Today, there are a number of coaching credentialing organizations. Currently the IAC and the ICF are the two largest providers of globally recognized, independent credentialing programs which have existed for more than a decade. "More than 21,000 coaches currently hold one of three offered ICF Credentials" (International Coach Federation, 2017, para. 2). As the ICF (2017) explains, ICF Credentials are highly recognized coaching qualifications with credibility around the world. The mission of the ICF Credentialing program includes protecting and serving consumers of coaching services, measuring and certifying the competence of individual coaches, and inspiring the pursuit of continuous development. 
Currently the ICF has three levels: Associate Certified Coach, Professional Certified Coach, and Master Certified Coach. Each credential requires a specific set of required hours of coach-specific training and coaching experience. The program establishes and administers minimum standards for credentialing professional coaches and coach training agencies; assures the public that participating coaches and coach training agencies meet or exceed these minimum standards; and reinforces professional coaching as a distinct and self-regulating profession.

Credentialing can enhance one's credibility in several ways: it "reassures potential coachees that you are an experienced and professional coach; demonstrates that you have high professional standards; demonstrates that you stand by a strong code of ethics; demonstrates a high knowledge and skill level; demonstrates that you take on-going professional development seriously; develops you as a professional coach to further enhance your skills; brings personal satisfaction in achieving a career goal, and reinforces the integrity of the coaching profession internationally" (International Coach Federation, 2017). It is evident that credentialing benefits the coaching profession by establishing a well-respected standard for credibility.

\section{Coach-Centric Contexts}

Aside from the standards of the ICF, professional coaching continues to be unregulated regarding the qualifications of a professional coach (Brotman, Liberi, \& Wasylyshyn, 1998; Judge \& Cowell, 1997). Indeed, as Grant (2007) asserts, there are currently no generally accepted, identifiable, and distinct skills for coaches. Instead, the practitioner literature has emphasized, from the coach's perspective, skills and characteristics that coaches need in order to be most effective. Moreover, one finds a healthy debate in the literature among practicing professional coaches and researchers as to who is most qualified to be a professional coach (Brotman et al., 1998; Diedrich \& Kilburg, 2001; Kampa-Kokesch \& Anderson, 2001; Kilburg, 1996; Levinson, 1996; Saporito, 1996; Sperry, 1993; Tobias, 1996). Next, we will explore the coaching skills

and characteristics that have evolved through a survey of existing coach-centric research.

\section{Coach Skills and Characteristics}

According to Brotman et al. (1998), executive coaches are characterized by the ability to facilitate sustained change in behavior. The executive is coached to display change in the targeted behavior(s). This change is consistent, 
even under pressure or stress. The new behavior is sustained by the internalization of deeper psychological insights about undesirable behavior(s) and targeted coaching that converts the insights into pragmatic action steps. This includes, (1) identifying habitual self-defeating scripts and learning how the adverse elements of the scripts erode leadership effectiveness, (2) revealing the truth and fresh insights into what drives the executive, (3) converting insights into observable behavior change, (4) distinguishing between healthy and more primitive defenses and (5) operationalizing the self-actualization pattern congruent with business objectives and the executive's aspirations. Tricky situations involving criticism and blame can be used to facilitate interactional change. The role of the executive coach entails inviting personal and focused criticism and utilizing a meta-perspective, as well as anchoring the conversation in the present situational interaction (Brotman, et al., 1998). These competences and competencies provide some of the important outcomes to be achieved in an executive coaching intervention but do not describe the process in an integrated model (Koortzen P., Oosthuizen, R., 2010).

According to Sperry (2007), some of the advantages of external coaches are anonymity, confidentiality, experience in many businesses, expertise in political nuances, being less likely to evaluate and judge, expertise based on extensive experience and being more objective (Sperry, 2007). Gender does not matter in a coaching relationship - communication is the main consideration. Research has shown that gender, combined with age and position, is sometimes a factor. There is the potential for unethical behavior. Each organization should develop its own coaching code of ethics to govern decisions about how coaches are assigned to executives and managers. Further qualities identified by Brotman et al. (1998) are being a trusting and approachable person, being comfortable with different types of people (including top management), having compassion and creativity, being intelligent and having interpersonal and political savvy and sound self-knowledge (Koortzen, P., Oosthuizen, R., 2010).

The services of a coach are diverse and may include helping to manage stress, meet job requirements, improve interpersonal relations, increase organizational effectiveness, avoid career derailment, manage change more effectively, set priorities, and make difficult decisions (Diedrich, 1996; Hall, 1999; Natale \& Diamante, 2005). The ultimate goal of coaching is often to benefit the organization as well as the individual. According to Kilburg (2004), "The focus nearly always remains on how to help people [executives] who have already demonstrated a great deal of competence and success get even better at what they do" (p. 204). In simple terms, the reason for coaching is to "allow for ongoing, continuous learning, while offering support, encouragement, and 
feedback as new approaches are tried and new behaviors practiced" (Tobias, 1996, p. 87). In this manner, the coaches help executives by challenging them toward their potential while addressing resistance. In the end, this process sets the stage for continuous learning and ultimately for change.

Kilburg (1996) adopted principles from Weinberger (1995) that focus on specific outcomes of the coaching process: (1) establishing an intervention agreement, (2) building a coaching relationship, (3) creating and maintaining expectations of success, (4) providing experiences of mastery and cognitive control, and (5) evaluating and attributing coaching successes and failures. To flesh out these components further, Kilburg identifies with the first element establishing a and goals for the coaching partnership, securing confidentiality, estimating a time commitment, and establishing fees. In the second element, Kilburg states the need for building an alliance and gaining commitment. He does not specifically expand on the third component; however, this may be considered to be straightforward. The fourth component of the executive coaching process, according to Kilburg, is mastery and cognitive control. This can be exemplified through using coaching techniques and methods with flexibility, problem solving, identifying and understanding emotions, employing feedback and disclosure with maximum effort, and being prepared to confront acting out and moral concerns of ethical misjudgments in a diplomatic manner. The fifth component, according to Kilberg, is to check in on the coaching and to assess the relationship to make sure that it is working well.

The following represents the most commonly found coach-centric skills and characteristics that lead to effective professional coaching experiences, as evident in the surveyed research. Having surveyed the research, the coachcentric skills and characteristics can be summarized as follows:

1. Coaches the whole coachee and pays attention to the interaction between the coachee's professional and personal life.

2. Challenges the coachee to think about new ideas and perspectives.

3. Holds the coachee accountable for doing the work. Insists that the coachee take action and create results.

4. Takes a multifaceted approach toward assessing the coachee's developmental needs, using relevant assessments, observations and interviews from stakeholders (boss, peers, team members, direct reports) that are critical to the coachee's development. 
5. Delivers immediate competency and action-oriented feedback on the coachee's developmental goals and progress.

6. Is non-judgmental, caring and supportive of the coachee's situation and needs.

7. Makes the coachee feel safe and can enable the coachee to trust the coach with issues of confidentiality.

8. Understands the coachee's pressures, challenges, responsibilities and industry in which they work and designs the coaching experience with all of this in mind.

9. Engages immediately and quickly identifies core developmental issues. Helps the coachee understand the gap between their intention and the impact that they have on others.

10. Listens more than they talk.

11. Asks relevant, probing questions and gets the coachee to process his or her thoughts and ideas.

12. Grounds the coaching experience around the coachee's developmental agenda and goals.

13. Motivates the coachee by recognizing his or her accomplishments when he or she loses focus or becomes discouraged.

14. Brings the coachee back to the reason for the coaching and intended outcomes/benefits.

15. Stays aware of and does not allow his or her own style, preferences, and feelings to influence the coaching process.

16. Models the behaviors and competencies that the coachee needs to develop.

17. Provides the coachee with practical ideas and strategies that he or she can put into action.

18. Remains knowledgeable, up-to-date and appropriately uses varying activities, exercises, tools, and conceptual models and theories to help the coachee develop.

19. Helps the coachee to identify and set clear developmental objectives, goals and assignments.

20. Is dependable and follows through on what was promised. 
21. Understands business, organizations, economic concepts and issues of management and leadership.

22. Is responsive, readily available and follows through on what is promised. Flexes to meet the coachee's changing context and goals.

23. Has a wide range of educational and coaching experience in different industries and in working with professionals across varying developmental career paths.

24. Consistently shows up to the coachee's coaching sessions with a positive, optimistic and friendly attitude.

(Brotman et al., 1998; Diedrich \& Kilburg, 2001; Kampa- Kokesch \& Anderson, 2001; Kilburg, 1996; Levinson, 1996; Saporito, 1996; Sperry, 1993; Tobias, 1996).

\section{Coachee-Centric Contexts}

There have also been several studies, from the perspective of the coachee, as to why they choose to engage in professional coaching (Hall, 1999). Even more impressive and now replete in the literature has been the rise in impact studies, again from the perspective of the coachee, that seek to understand the benefits and/or outcomes of the professional coaching experience (KampaKokesch \& Anderson, 2010; McGovern, 2001; Wasylyshyn, 2003).

Despite this empirical focus on the coachee, little is known about those responsibilities, motivations, characteristics, and other competencies responsible for influencing the effectiveness of a professional coaching experience. As a result, the list of the coachee characteristics is noticeably shorter than the review of the coach-centric skills and characteristics. The coachee characteristics' list begins with the most current studies and works backwards chronologically. Several studies had only one competency to report and, on those occasions, they were coupled with other studies from different years as a way to cluster the findings. Many researchers similarly reported the need for coachees to identify and set clear developmental objectives (Hall, 1999).

Stevens (2005) identified the following coachee-centric characteristics in his study:

1. Being fully present for each coaching session. 
2. Keeping appointments and commitments. Following through on completing their homework assignments.

3. Practicing new skills and behaviors needed for their development.

4. Taking an active role in involving all of their stakeholders (supporters and non-supporters) in the feedback process to ensure that they receive a full and real snapshot of how others perceive them.

5. Trusting their boss and organization's motives for enrolling them in coaching.

6. Choosing to see professional coaching as an opportunity to take advantage of.

7. Stopping to reflect and recognize their efforts and celebrating their successes along the way.

8. Taking risks and doing whatever it takes to make changes.

Stevens (2005) reported adherence as a critical coachee-centric characteristic that leads to effective professional coaching. According to Stevens (2005), the term "adherence" comes from clinical psychology and refers to the "willingness of the coachee to engage and remain focused in the therapy. Applied to coaching, the coachee enters the coaching engagement with the idea that he or she will benefit and that he or she will engage the coach and the process" (p. 85). Stevens' emphasis on adherence is supported by the extensive work of Goldsmith (2012), while Ducharme (2004) states "it is a strong requirement of the coaching process that those who enter into a relationship with a professional coach are committed to the relationship and feel comfortable with the format and process" (p. 130). McGovern (2001) discusses the need for coachees to voluntarily set and commit to their coaching goals.

Bush (2004) reported several coachee-centric findings in her research that were central to increasing the effectiveness of a professional coaching experience:

- Having realistic expectations of what they are actually able to accomplish/gain.

- Being conscious of not trying to change or improve in too many areas at once.

- Being "coachable" and open to the results of the feedback from his or her coach. 
- Considering their coach's ideas, influence and perspective on his or her behavioral and performance issues.

- Breaking down and working on his or her developmental goals in concrete, measurable steps.

- Holding the focus of his or her developmental goals and not allowing themselves to be sidetracked by other organizational distractions and "crises."

- Taking the time and making the effort to clarify upfront what he or she needs/wants from the coaching experience and setting clear developmental goals.

Bush (2004) summarized her findings by stating, "The coachee brings motivation, willingness to be coached, openness to the process, and a commitment to do the work" (p. xi).

Sztucinski (2001) identified several additional coachee-centric characteristics as influencing the effectiveness of his or her executive coaching experience:

1. Committed to Coaching \& Doing the Work (making time for the process, doing the homework, following up and practicing new skills and behaviors).

2. Healthy and Mature (coachee is psychologically mature and healthy enough to engage in the process).

3. Ready to Learn/Develop (coachee drive/motivation for learning; resolving issues and developing potential is present; open to feedback and capable of considering performance issues from a different point of view; open to coach's influence and help).

4. Capable of Clarifying/Setting Coaching Goals (coachee is capable of clarifying upfront what is needed/wanted from the coaching; is able to set clear developmental goals).

\section{Coach Skills and Degrees of Professional Coaching Effectiveness Study Methodology}

This study used a survey research design to determine the competencies that most commonly lead to an effective coaching experience, from the coach's as well as the coachee's perspective. 
This study is based on the competencies discussed in the literature review and reported to lead to effectiveness. The study focused on the competencies evident in Bush's (2004) qualitative research findings (coach and coachee competencies) that lead to executive coaching effectiveness and the International Coach Federation core competencies (for the coach) (p. 155).

The primary research question that guided this study was "What specific competencies in executive coaching lead to the most effective coaching experiences and which are the most frequently cited competencies that contribute to the overall effectiveness of coaching from the perspective of the coach?" The second research question was "What relationship exists between the degrees of executive coaching effectiveness and executive coaching competencies?"

\section{Research Design}

A survey was used in this study to describe from the point of view of the coachee and from the coach what competencies most commonly lead to effectiveness in executive coaching. Structured surveys and questionnaires are among the most utilized data collection methods inside of quantitative research designs and were utilized in this study (Greif, 2007). A structured, internetbased survey was used to describe which executive coaching competencies most frequently lead to effective coaching experiences. Closed-ended, Likerttype scale and forced choice response statements were formed around the research-based competencies. These competencies were based on the findings of the study as well as the ICF core competences/coaching competencies.

Coach-centric competencies have received the bulk of attention from researchers, whereas much less is known about coachee- and context-centric competencies. Consequently, survey response options were predetermined and presented as a deductive list of coach, coachee, and context-centric competencies.

Research participants were asked to evaluate the effectiveness of their coaching experience across a six-point Likert scale and were also prompted to make forced choices across the numerous competencies. Furthermore, this study allowed for one additional qualitative, open-ended question that solicited perspectives about additional competencies the research participant believed led to coaching effectiveness, and that were not present in the forced choice scales. This question permitted additional feedback from each research participant that the survey did not anticipate. 
The results of this review allowed for specific competencies to be named and then classified into three areas: coach, coachee and context-centric competency areas. This classification in turn led to the sum of competencies necessary for effectiveness in coaching from the coachee's perspective. The effectiveness questionnaires, including the email invitation and consent form, were reviewed upon completion. The email invitation, research study consent form, and the effectiveness questionnaire appear as appendices in this study.

\section{Sampling Design}

A convenience sample was used in this study on the basis of availability and ease of data collection, where respondents self-selected to participate. As a current member of the International Coach Federation, my access to the ICF members was facilitated by the ICF board of directors.

The following criteria were used to qualify the sample for this study:

1. All respondents self-selected to contribute to what is known about the effectiveness of executive coaching.

2. All respondents were accessed from the International Coach Federation member database. This database houses thousands of ICF members.

3. The ICF coach members then sent the coachee survey to their identified coachees.

4. All coachee respondents were current or former coachees of ICF member coaches (coachees have engaged in some form of executive coaching).

The total sample population for this survey was 157 coaches and 70 of their coachees.

\section{Data Collection Procedures}

The ICF database houses and tracks thousands of coaches who are members of the International Coach Federation. This database was used to send the coach effectiveness survey to all ICF members. Research participants were invited to participate in the study via email survey. The invitation email served as the first point of contact and provided information regarding the purpose of the research study, background information on Benedictine University, how to contact the researcher and the researcher's committee chair, and the electronic link to the online survey. 
The online survey platform SurveyMonkey was customized to meet the needs of this study. Upon clicking on the electronic link in the email invitation, participants were directed to the Welcome Page of the SurveyMonkey survey. Research participants were then guided through a screen-by-screen survey format where they had to complete all questions on each screen prior to moving to the next screen. The survey began with an initial consent screen that required respondents to check several agreement statements confirming that they had read and met the sample criteria for the study. The survey questions were presented to the research participants upon their full completion of the consent form and after having completed several questions seeking demographic information. All survey data was collected and stored on the SurveyMonkey website until the study was complete. The data was then transferred onto the researcher's computer. The data analysis began once the download of survey data had been completed.

\section{Instrumentation}

The online surveys began with four questions designed to secure participant consent, followed by nine specific demographic questions. The first overarching question in the survey was designed to identify to what degree the respondent found the executive coaching experience effective (as the coachee and as the coach, which were assessed separately). The following three survey sections included six competency specific questions that fell within each coaching competency area, beginning with coach and followed by coachee competencies. These competencies were those identified through the literature review conducted in Chapter 2. The survey utilized a structured six-point Likert-type scale to first determine the degree of effectiveness of the coaching experience. The following six-point scale was used to force the respondent to either side of the scale:

$$
\begin{aligned}
& \text { 1= Very Ineffective } \\
& 2=\text { Ineffective } \\
& 3=\text { Somewhat Ineffective } \\
& 4=\text { Somewhat Effective } \\
& 5=\text { Effective } \\
& 6=\text { Very Effective }
\end{aligned}
$$


Upon answering the degree of effectiveness question, participants were then "forced" (forced choice methodology) to pick the top seven competencies of the total number of competencies that most contributed to effectiveness in each competency area. The participant was guided to one of two possible questions to determine the top seven competencies per competency area depending on whether they characterized the degree of effectiveness of the participant's coaching from 1-3 or from 4-6. When participants characterized the coaching experience as "somewhat effective," "effective," or "very effective" (degrees 4-6), they were asked to evaluate all of the competencies only as they experienced the coaching. When participants characterized their coaching experience as "somewhat ineffective," "ineffective," or "very ineffective" (degrees 1-3), they were asked to evaluate all of the competencies based on what they believed would have led to a more effective experience. Upon selecting the top seven competencies inside of each competency area, the participants were then guided to a screen that displayed the seven competencies they selected; at this point they were asked to rank order their top seven competencies. This additional step in the process provided another critical layer of data and allowed for the creation of an "importance scale" during the analysis. After the rank order question, participants were asked to identify "other" competencies, in written format, that led to their coaching effectiveness yet were not available within the predetermined survey options. This allowed new competencies to emerge that were not evident in the literature review.

The survey comprised twenty-three questions, including the demographic and consent questions. Research participants are sensitive to survey length (Jobber, 1996), and studies show that shorter survey lengths produce higher response rates.

\section{Data Analysis Procedures}

The SPSS (Statistical Package for the Social Sciences) was used to manage the descriptive statistics generated from the Coaching Effectiveness Questionnaire. The data analysis options used in this study included frequency distribution and measures of central tendency (mean, mode, median) and variability. Frequency distribution reported the number of times and overall percentages with which specific demographic variables were selected, as well as how often coaching competencies were selected within each competency area (coach, coachee, and organization/contextual). The mean (measure of central tendency and the mathematical average and middle point of the data) was calculated in order to depict the average rank of each survey competency. 
This calculation was critical in producing an "importance ranking" for each competency, relative to how frequently it was chosen.

The Pearson's chi-square test was also calculated in order to determine whether there were relationships between coaching competencies and the demographic information, as well as the high and low degrees of coaching effectiveness. The Pearson's chi-square test compares the frequencies observed in a categorical group with the frequencies one might expect to get in those categories by chance (Field, 2005). Frequency distribution, average rank, and chi square results are graphically represented in table form in this study

\section{Ethical Issues}

Research participants invited to this study were informed that their participation was completely voluntary. Participants were told that this research was being conducted for a dissertation and that the results would be used to establish a stronger foundation for what leads to effective executive coaching from the coachee's perspective. They were also notified that their consent to participate in this research would be assumed upon their completion of the survey's executive coaching effectiveness questionnaire.

This study was designed using standard procedural safeguards and ethical considerations as required by the Benedictine Institutional Review Board. Strict procedural safeguards were created in order to maintain the confidentiality of participant data. Specifically, neither participant names nor addresses were solicited in this study, and all responses were anonymous. All collected data was transferred from the Survey Monkey website onto the researcher's restricted-access computer. Consequently, participant risk was thought to be low throughout the study, and respondents should have experienced no discomfort as they filled out the survey, given the numerous safeguards.

Furthermore, the results of this study may benefit those participants who read through a final copy of the study results. Study participants may become more aware of their coaching experience and the changes they made by reading through the study results, and this awareness may allow them to reconnect with or generate new developmental goals for themselves. 


\section{Coach Skills and Degrees of Professional Coaching Effectiveness Study Results}

Nineteen industry sectors were represented within the response results, while the majority of the survey respondents identified working in the industries of education (31.2\%), manufacturing (7.6\%), non-profit $(5.7 \%)$, healthcare $(5.7 \%)$, and technology $(5.7 \%)$. Roughly $73.2 \%$ of respondents work in the organizational levels of executive, upper-middle or middle management tiers, and $48.4 \%$ of all respondents have been coaching for more than 5 years. Leadership skill improvement served as the greatest reason for coachees seeking out and participating in executive coaching (42.7\%), followed by career development $(22.9 \%)$ of all respondents. One hundred twenty-six $(80 \%)$ indicated they have four hundred hours of executive coaching experience. A majority of respondents indicated that their coachees engaged in executive coaching on a bi-monthly basis (65\%). "Caucasian" was most often selected $(42 \%)$ as the ethnic/cultural identifier. The United States was selected by 52 respondents as their country of origin (32.5), followed by England (17.2\%) and Canada $(9.6 \%)$.

The first survey question sought to ascertain the degree to which each respondent believed that her/his coaching experience was effective. Ninety-one of the total 157 respondents identified their executive coaching experience as "very effective"; 45 respondents (55.0\%) identified their coaching experience as "effective"; $15(9.6 \%)$ believed their coaching experience rated as "somewhat effective"; and 6 respondents $(3.8 \%)$ selected "very ineffective."

The primary research question of this study "What are the most frequently cited competencies that contribute to the effectiveness of an executive coaching experience?" produced the top seven most commonly cited competencies per competency area (coach and coachee). The results of these top seven competencies are presented in Table 1 for easier comparison. 
Table 1: Top seven most commonly cited competencies per competency area

\begin{tabular}{|l|l|}
\hline $\begin{array}{l}\text { Coach Characteristics (top seven } \\
\text { by frequency \& percentage) }\end{array}$ & $\begin{array}{l}\text { Coachee Characteristics (top seven by } \\
\text { frequency \& percentage) }\end{array}$ \\
\hline $\begin{array}{l}\text { Asks relevant, probing questions and gets } \\
\text { the coachee to process their thoughts and } \\
\text { ideas. (n=114, 75.5\%) }\end{array}$ & $\begin{array}{l}\text { Being fully present for each coaching } \\
\text { session. (n=117, 77.5\%) }\end{array}$ \\
\hline $\begin{array}{l}\text { Makes the coachee feel safe and can } \\
\text { enable the coachee to trust the coach with } \\
\text { issues of confidentiality. (n=114, 75.5\%) }\end{array}$ & $\begin{array}{l}\text { Taking the time and making the effort to } \\
\text { clarify upfront what they need/want from } \\
\text { the coaching experience and setting clear } \\
\text { developmental goals. (n=120,79.5\%) }\end{array}$ \\
\hline $\begin{array}{l}\text { Challenges the coachee to think about } \\
\text { new ideas and perspectives. (n=105, } \\
69.5 \%)\end{array}$ & $\begin{array}{l}\text { Taking risks and doing whatever it takes } \\
\text { to make changes. (n=11, 73.5\%) }\end{array}$ \\
\hline $\begin{array}{l}\text { Coaches the whole coachee and pays } \\
\text { attention to the interaction between the } \\
\text { coachee's professional and personal life. } \\
\text { (n=96, 63.6\%) }\end{array}$ & $\begin{array}{l}\text { Practicing new skills and behaviors } \\
\text { needed for their development. (n=99, } \\
65.6 \%)\end{array}$ \\
\hline $\begin{array}{l}\text { Holds the coachee accountable for doing } \\
\text { the work. Insists that the coachee takes } \\
\text { action and creates results. (n=78, 63.6\%) }\end{array}$ & $\begin{array}{l}\text { Breaking down and working on their } \\
\text { developmental goals in concrete, } \\
\text { measurable steps. (n=93, 61.6\%) }\end{array}$ \\
\hline $\begin{array}{l}\text { Is non-judgmental, caring and supportive } \\
\text { of the coachee's situation and needs. } \\
\text { (n=78, 51.7\%) }\end{array}$ & $\begin{array}{l}\text { Being "coachable" and open to the results } \\
\text { of the feedback from the coach. } \\
\text { Considering the coach's ideas, influence } \\
\text { and perspective of their behavioral and } \\
\text { performance issues. (n=93, 61.6\%) }\end{array}$ \\
\hline $\begin{array}{l}\text { Helps the coachee to identify and set } \\
\text { clear developmental objectives, goals and } \\
\text { assignments. (n=75, } 49.7 \%)\end{array}$ & $\begin{array}{l}\text { Stopping to reflect and recognize their } \\
\text { efforts and celebrating their successes } \\
\text { along the way. (n=63, 41.7\%) }\end{array}$ \\
\hline
\end{tabular}




\section{The Coaching Characteristics Effectiveness Model}

Figure 1 presents the coaching effectiveness model developed as a result of the Coach Skills and Degrees of Professional Coaching Effectiveness Study (Boysen-Rotelli, 2012). The figure cites each of the top seven skills and competencies for both the coach and the coachee.

Figure 1: Coaching Effectiveness Model (Boysen-Rotelli, 2012, p. 122)

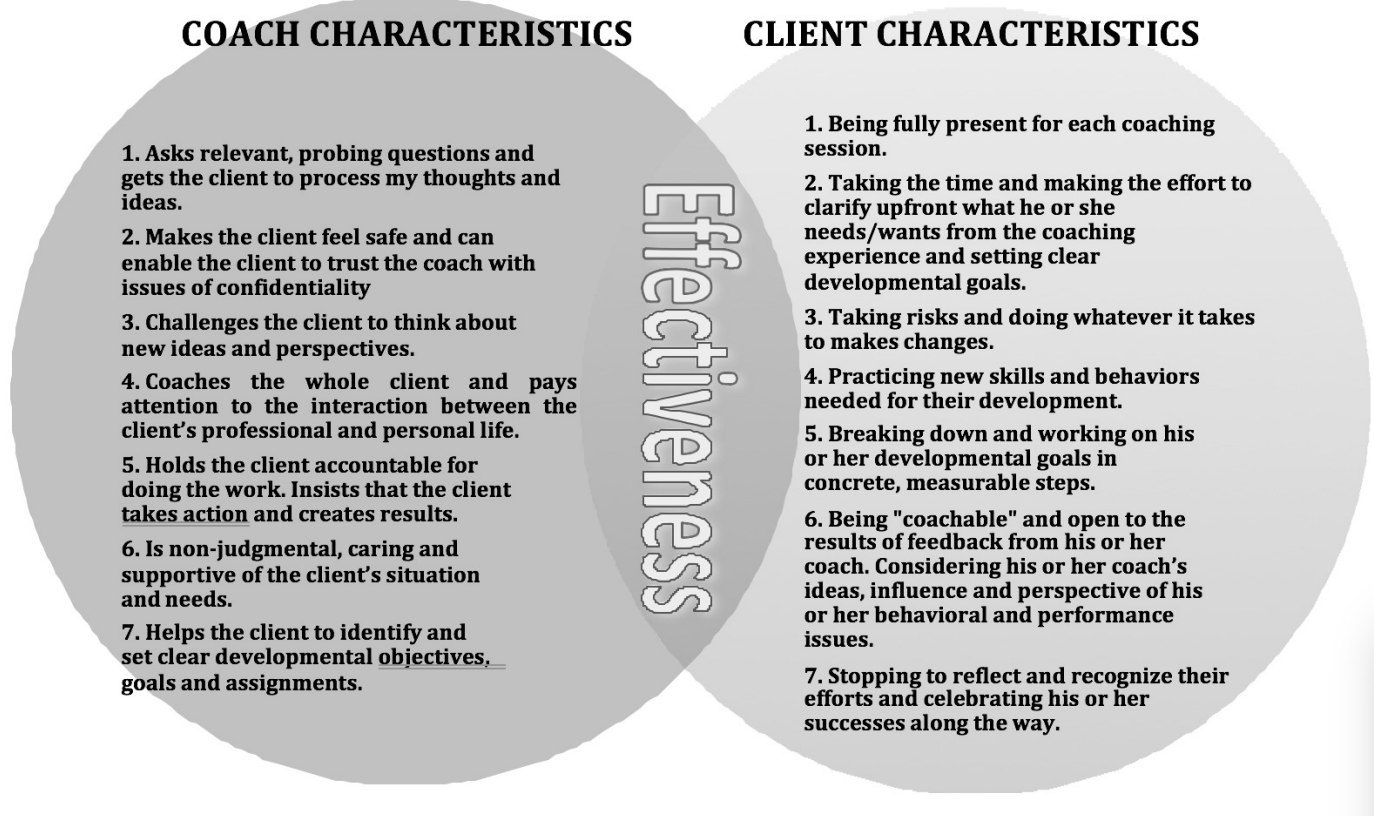

\section{Alignment with the Core Competencies}

There is direct alignment between these coaching skills and the ICF core competencies. This can be seen in Table 2 .

The alignment between the ICF Core Competencies and the skills that are part of the Coaching Effectiveness Model is clear. These additional skills are not in conflict with the 11 Core Competencies, but rather, complement them and support them deeply. 
Table 2: ICF Core Competencies Alignment with the Skills in the Coaching Effectiveness Model

\begin{tabular}{|c|c|}
\hline ICF Core Competencies & Coaching Effectiveness Model \\
\hline Powerful Questioning & $\begin{array}{l}\text { Asks relevant, probing questions and gets the coachee } \\
\text { to process his or her thoughts and ideas. }\end{array}$ \\
\hline $\begin{array}{l}\text { Establishing Trust and Intimacy } \\
\text { with the Coachee } \\
\text { Meeting Ethical Guidelines and } \\
\text { Professional Standards }\end{array}$ & $\begin{array}{l}\text { Makes the coachee feel safe and can enable the } \\
\text { coachee to trust the coach with issues of } \\
\text { confidentiality. }\end{array}$ \\
\hline Direct Communication & $\begin{array}{l}\text { Challenges the coachee to think about new ideas and } \\
\text { perspectives. }\end{array}$ \\
\hline $\begin{array}{l}\text { Establishing the Coaching } \\
\text { Agreement }\end{array}$ & $\begin{array}{l}\text { Coaches the whole coachee and pays attention to the } \\
\text { interaction between the coachee's professional and } \\
\text { personal life. }\end{array}$ \\
\hline $\begin{array}{l}\text { Managing Progress and } \\
\text { Accountability } \\
\text { Designing Actions }\end{array}$ & $\begin{array}{l}\text { Holds the coachee accountable for doing the work. } \\
\text { Insists that the coachee take action and create results. }\end{array}$ \\
\hline $\begin{array}{l}\text { Active Listening } \\
\text { Coaching Presence }\end{array}$ & $\begin{array}{l}\text { Is non-judgmental, caring and supportive of the } \\
\text { coachee's situation and needs. }\end{array}$ \\
\hline $\begin{array}{l}\text { Planning and Goal Setting } \\
\text { Creating Awareness }\end{array}$ & $\begin{array}{l}\text { Helps the coachee to identify and set clear } \\
\text { developmental objectives, goals and assignments. }\end{array}$ \\
\hline
\end{tabular}


The Coach Skills and Degrees of Professional Coaching Effectiveness Study sought to better understand the complexity of the executive coaching experience by exploring and describing the multiple skills and characteristics that are necessary for effectiveness in an executive coaching experience, from the coach's and coachee's perspective (Boysen-Rotelli, 2012). This study has taken the field one-step further with scholarly research about the skills and characteristics that lead to effectiveness. In total, this study utilized the voices of 157 coaches to represent, through the coaching effectiveness model, the most important skills and characteristics for executive coaching effectiveness.

The findings of this non-experimental descriptive study presents the top seven most commonly cited coach and coachee competencies, from the coach's perspective, necessary for executive coaching effectiveness. The coaching effectiveness model provides the coach, the coachee, the organization sponsoring the coachee's development, and the researcher a quantitative bird'seye view of what has been identified as necessary for effectiveness in the coaching engagement. This study and the findings of this study have addressed the requests of researchers calling for more systemic approaches to exploring the complexity of executive coaching. To this end, the results of this present study have brought into focus a view of the entire executive coaching effectiveness phenomenon.

\section{Limitations}

This study used one method of data collection, the survey, and did not allow for additional deeper analysis of issues that arose from the survey. Issues that went beyond the scope of this study are presented as recommendations for future research.

All research participants in this study received certification through the International Coach Federation (ICF). Thus, collected data represents the sole perspective of participants who were certified by the ICF. Therefore, the findings of this study may not generalizable across all executive coaches.

\section{Summary}

There is no question that the executive coach is the lynchpin of the executive coaching experience, working hard to ensure improved coachee performance and that the coachee doesn't slip off of his or her developmental pathway. There's a stark reality however, that the executive coach is the "developmental leader" and he or she can only lead the coachee to the 
proverbial "developmental water." The results of this study should serve as a reminder that executive coaching effectiveness is contingent upon not only a good coach, but that the coachee must also engage fully in the work and sometimes this work is hard. Given the overabundance of practice and academic literature swirling around the executive coach, there seems to be a developmental laziness or belief that the coachee's answers reside "out there or with the coach." Maybe coachees, as recipients and beneficiaries of the service, will begin to hold themselves more accountable as the messages in the marketplace begin to communicate that they themselves can make or break the executive coaching effectiveness equation.

\section{References}

Boysen-Rotelli, S. (2012). Executive coaching effectiveness: A qualitative study (Doctoral dissertation). Retrieved from ProQuest.

Brotman, L. E., Liberi, W. P., \& Wasylyshyn, K. M. (1998). Professional coaching: The need for standards of competence. Consulting Psychology Journal: Practice and Research, 40(1), 40-46.

Corporate Leadership Council. (2017.). [Summary of research: professional coaching]. Unpublished raw data.

Ducharme, M. J. (2004). The cognitive-behavioral approach to professional coaching. Consulting Psychology Journal: Practice and Research, 56(4), 214-224.

Grant, A. M. (2007). A languishing-flourishing model of goal striving and mental health for coaching populations. International Coaching Psychology Review, 2(3), 250- 264.

Greif, S. (2007). Advances in research on coaching outcomes. International Coaching Psychology Review, 2(3), 222-242.

Goldsmith, M., Lyons, L., \& Freas, A. (Eds.). (2000). Coaching for leadership: How the world's greatest coaches help leaders learn. San Francisco, CA: John Wiley and Sons.

Hall, D. T., Otazo, K. L., \& Hollenbeck, G. P. (1999). Behind closed doors: What really happens in professional coaching. Organizational Dynamics, 27(3), 39-54.

International Coach Federation. (2017). Coaching core competencies. Retrieved, May 17, 2017, from http://www.coachfederation.org/ICF/For+Current+Members/Credentiali ng/Why+a+Credential/Competencies/

Judge, W. Q., \& Cowell, J. (1997, July/August). The brave new world of professional coaching. Business Horizons, 71-77. 
Kampa-Kokesch, S., \& Anderson, M. Z. (2010). Professional coaching: A comprehensive review of literature. Consulting Psychology Journal: Practice and Research, 53(4), 205-228.

Kilburg, R. R. (1996). Toward a conceptual understanding and definition of professional coaching. Consulting Psychology Journal: Practice and Research, 48(2), 134- 144.

Koortzen, P., Oosthuizen, R. (2010). A competence executive coaching model. SA Journal of Industrial Psychology, 36(1).

McGovern, J., Lindemann, M., Vergara, M., Murphy, S., Barker, L., \& Warrenfeltz, R. (2001). Maximizing the impact of professional coaching: Behavioral change, organizational outcomes, and return on investment. The Manchester Review, 6(1), 1-9.

Morse, J. M., \& Richards, L. (2002). Read me first for a user's guide to qualitative methods. Thousand Oaks, CA: Sage.

Saporito, T. J. (1996). Business-linked professional development: Coaching senior professionals. Consulting Psychology Journal: Practice and Research, 48(2), 96- 103.

Sperry, L. (1993). Working with professionals: Consulting, counseling, and coaching. Individual Psychology, 49(2), 257-267.

Stevens, J. H., Jr. (2005). Professional coaching from the professional's perspective. Consulting Psychology Journal: Practice and Research, 57(4), 274-285.

Sztucinski, K (2001). The nature of executive coaching: An exploration of the executive's experience. The George Washington University, District of Columbia.

Tobias, L. L. (1996). Coaching professionals. Consulting Psychology Journal: Practice and Research, 48(2), 87-95.

Wasylyshyn, K. M. (2003). Professional coaching: An outcome study. Consulting Psychology Journal: Practice and Research, 55(2), 94-106.

Whitworth, L., Kimsey-House, H., \& Sandahl, P. (2010). Co-active coaching: New skills for coaching people toward success in work and life. Palo Alto, CA: Davies-Black. 